\title{
Towards Ethical Guidelines of Using Telepresence Robots in Residential Care
}

\author{
Marketta Niemelä $^{1}$ D $\cdot$ Lina van Aerschot ${ }^{2} \cdot$ Antti Tammela $^{1} \cdot$ lina Aaltonen $^{1} \cdot$ Hanna Lammi $^{1}$
}

Accepted: 5 February 2019 / Published online: 22 February 2019

(c) The Author(s) 2019

\begin{abstract}
Robotic telepresence is a potential technology to help alleviating the loneliness of elderly people. The impacts of long-term use of telepresence robots in residential care are not well known. We were interested in how using a telepresence robot influences the resident, family members and care workers at a facility, and what challenges and solutions there are for wider adoption of such robots in residential care. With a telepresence robot Double, we arranged a series of three trials in two separate residential care facilities: one 12-week trial in a private facility and two successive 6-week trials in a public facility. In each trial, we installed the telepresence robot in a room of a long-term care home resident for communicating with her/ his family members. Based on the results, telepresence robots do increase presence and possibly engagement of family members in residential care, but privacy is a central concern. The mobility of a telepresence robot is hard to utilize in residential care, and to be able to do so, ethical consideration and guidelines are needed. We provide a draft of such ethical guidelines.
\end{abstract}

Keywords Elderly $\cdot$ Residential care $\cdot$ Telepresence robot $\cdot$ Social relationships $\cdot$ Privacy $\cdot$ Ethical guidelines

\section{Introduction}

Loneliness and depression are serious concerns for elderly people living in care facilities [1,2]. Communication and contacts with family and friends are among the most important aspects in supporting the well-being of people. Therefore, to increase their quality of life, elderly people in residential care should be offered more possibilities for participation, social activities and maintaining social relations - this approach can be called person-centered care [3].

Marketta Niemelä

marketta.niemela@vtt.fi

Lina van Aerschot

Aerschot@vtt.fi; lina.vanaerschot@jyu.fi

Antti Tammela

antti.tammela@vtt.fi

Iina Aaltonen

iina.aaltonen@vtt.fi

Hanna Lammi

hanna.lammi@vtt.fi

1 VTT Technical Research Centre of Finland Ltd, Tampere, Finland

2 University of Jyväskylä, Jyväskylä, Finland
Telepresence is a potential technology to alleviate loneliness by allowing friends and family members to be virtually present for the elderly person (e.g. [4]). Telepresence robots (e.g., Beam, VGo, Giraff and Double), also known as virtual presence or remote presence robots, are remote-controlled robotic devices which enable a person not just to be virtually present, interact and socially participate from a remote location, but also physically move in the robot's local environment, so allowing the remote user to take more control over her/his presence. ${ }^{1}$

For elderly persons, robotic telepresence provides benefits compared to non-mobile video connection [7]: because of the remote control of the robot, the elderly user can interact with it in a natural manner, with little additional learning. The remote user having the control of the robot can more flexibly adapt to the physical requirements of the elderly person, for instance, by moving closer to her/him. A telepresence robot is adjustable for many kind of uses, for both mobile and less mobile elderly users, who may also want to

\footnotetext{
1 Some advanced robotic systems such as Telenoid or Geminoid also provide robot-mediated social presence of a remote person to a local user interacting with the robot. These systems are rather described as teleoperated android robots than telepresence robots $[5,6]$. Telenoid and Geminoid allow "anonymous interaction" as the local user may not know who is operating the robot; this out of the scope of our study.
} 
drive the robot themselves. The robot can increase the feelings of safety and connection as the elderly user knows that others can easily "stop by" virtually.

In addition to the benefits, many empirical studies have pointed out also potential drawbacks (see next chapter). However, fewer studies have been conducted in the context of residential care, and especially the perspective of care workers is not well understood. In this paper, we further elaborate what kind of social benefits, concerns and impacts are related to the use of a telepresence robot in residential care, from the perspectives of (1) a resident in a facility and her family and (2) the care workers involved in taking care of the resident. The data has been collected in three field trials of a telepresence robot in two residential care facilities (the results of the first trial have been earlier reported in [8]. In particular, we analyze the ethical (privacy) challenges that relate to mobile telepresence at a ward, and as a result, we present a draft of ethical guidelines for using telepresence robots in residential care.

\section{Background}

\subsection{Assisted Living: In Between Home and Institutional Care}

Assisted living is a combination of housing and basic nursing care. It holds a promise of ageing in place as the facility services adapt according to the residents' changing needs. This type of care is also called residential care [9]. The residences are often arranged to different units (e.g. separate wards of intensive care with determined daily routines) but inside people live in their own small apartments or rooms with a kitchenette and a bathroom. Unlike long-term care institutions, assisted living provides the resident a homelike environment to foster autonomy, privacy and freedom of choice [10, p. 216]. People in residential care can more easily make individual choices regarding the services they use, the daily routines and the ways of living [11]. This supports the individual well-being of the residents.

Yet, depression is common among older people. Persons in residential care are also at risk [12]. Despite the aim of providing a home-like environment and continuation of the lifestyle of their choice, many feel decreased privacy, and the common areas like dining rooms or living rooms are not felt as home-like [13]. Quality of life may suffer also because moving into a care facility is a significant change in the lives of older people. The earlier social surrounding changes completely and the old routines and habits are broken [14]. People may lose their everyday social contacts, and feel socially isolated [3, p. 64]. Furthermore, in Finland the municipal authorities decide on a person's entitlement to a place in residential care and often refer people to the care units according to the specific care needs and available places [15], not according to their wishes or preferences.

Thus, it is essential to support the social contacts and continuity of the social relationships between the residents in assisted living and their families and friends. Social engagement in the sense of making social and emotional connections with people and the community [16] has a positive effect on both physical health and social well-being of older people [17].

\subsection{Telepresence Robots for Elderly in Home and in Residential Care}

Telepresence robots have been tested in different settings for their potential to support social relationships for elderly people. Both lab and in-home short trials have reported mostly positive perceptions of mobile telepresence systems e.g., $[18,19]$. In addition, long-term studies of a telepresence robot supporting independent living have shown positive influences $[4,20]$. In particular, older people and their families have liked the possibility of seeing the remote person. There are many other benefits, such as reduced travel time for remote users and the appeal of the robot itself. The concerns raised in the home context have included the call etiquette (how to end/refuse call), the elderly person's (lacking) control over accepting/refusing calls, the lack of faceto-face contact, and mis/overuse of the system.

In residential care setting, similar results have been achieved. The tested robots have gained positive responses from elderly residents, their families, and healthcare professionals. In one study, a multifunctional assistive telepresence robot was placed in the nursing home for 1 month, and both the elderly users and professional caregivers found the robot useful for reducing loneliness and increasing contact with family and friends [21]. Telepresence provided positive emotional effect both sides: seeing the faces of family members maintains the resident's connection with them, and the family feels enjoyment and reassurance for seeing the resident is doing well.

Care facility as a use environment of a telepresence robot brings also new issues at stake [22]. Report a study in which a Giraff robot was used 6-8 weeks in a nursing home by five elderly participants, who suffered from mild to moderate dementia, and their family members. In addition to the general positive response and social effects, the family could get more involved in the life of the facility by being able to talk to staff. The ability to move around with the robot was reported beneficial for the family members, as they could observe places and follow the resident in the facility, although the privacy issue was in concern. The telepresence robot was preferred to existing video call applications because of the greater level of control the family has in terms of connecting, moving, and positioning 
Table 1 Benefits and concerns when using a telepresence robot in residential care

\begin{tabular}{|c|c|c|}
\hline & Benefits & Concerns \\
\hline Resident(s) & $\begin{array}{l}\text { Reduced social isolation, increased connection between the } \\
\text { resident and family members }[4,19-22] \\
\text { Especially being able to see the family member's face is impor- } \\
\text { tant to the resident }[4,18,21,22] \\
\text { Robot more interactive and appealing for communication than } \\
\text { phone [20] }\end{array}$ & $\begin{array}{l}\text { The resident may react negatively (be confused, frightened) [22] } \\
\text { Lack of physical face-to-face contacts due to reduced visits of the } \\
\text { family [20,22] } \\
\text { Mis/overuse of the robot [18] } \\
\text { The resident does not have enough control (to end/refuse a call } \\
\text { and to manage who has access) [18] } \\
\text { Invasions of privacy [22] }\end{array}$ \\
\hline Family & $\begin{array}{l}\text { Enjoyment when connecting to the resident; reassurance when } \\
\text { seeing that the resident is doing well [22] } \\
\text { Less guilt of not putting enough attention to the elder person } \\
\text { [20] } \\
\text { Reduced travel time and related convenience }[18,22] \\
\text { Family and staff discuss about care; the family feels more } \\
\text { involved and connected with the facility [22] }\end{array}$ & $\begin{array}{l}\text { Family members may witness residents' disruptive behavior [22] } \\
\text { Guilt because using the robot partially substitutes real visits [20] }\end{array}$ \\
\hline Staff & $\begin{array}{l}\text { Feeling good when seeing the resident experiencing enjoyment } \\
\text { [22] } \\
\text { Requires little effort from the staff, if the robot is easy to use } \\
\text { [23] }\end{array}$ & Staff may feel unskilled and too busy to learn [22] \\
\hline
\end{tabular}

Table 2 The primary users in the three field trials

\begin{tabular}{llll}
\hline Trial & Care facility & $\begin{array}{l}\text { Primary and secondary } \\
\text { users of the robot }\end{array}$ & Background of the primary user \\
\hline 1 & A & $\begin{array}{l}\text { Resident 1, F, 83 year. } \\
\text { Two daughters }\end{array}$ & $\begin{array}{l}\text { No diagnosed memory illness; mostly moved in a wheelchair. No experience of technology. } \\
\text { One daughter visits 2-3 times a week; the other calls 2-3 times a week. } \\
\text { Resident 2, M, 85 year. } \\
\text { Daughter } \\
\text { Resident 3, F, 93 year. } \\
\text { times a week. }\end{array}$ \\
Daughter; Son and his wife & $\begin{array}{l}\text { Some symptoms of memory illness. Hard of hearing. No experience of technology. The } \\
\text { daughter has just moved further away, calls every day. The son visits a few times a year } \\
\text { and calls 3-6 times a week. }\end{array}$ \\
\hline
\end{tabular}

the camera. The staff liked seeing the residents enjoying the communication with the family.

The participants expressed also concerns about whether the residents would react by confusion or fear to the robot, or would the family members witness residents' disruptive behavior. The staff felt unskilled and that they had no time to learn to use the robot. It has been pointed also elsewhere that the easiness of use of the robot, so that it requires minimum assistance from the facility staff, is essential [23].

The main benefits and concerns related to telepresence robots in residential care are collected in the Table 1 (partially published earlier in [8]). Telepresence robots appear to be a beneficial technology for older people in residential care and their families. The concerns related especially to privacy and control must be taken into account. The benefits and concerns for care workers and a telepresence robot's possible influences to their work are less clear, and care workers may find the robot as an extra workload. However, for telepresence robots to become common, their perspective and acceptance are critical.

\section{Study Setting}

The empirical study was carried out as three separate field trials, in which a telepresence robot Double (https://www. doublerobotics.com) was placed in the rooms of three longterm residents in two residential care homes (Table 2). The residents lived at wards of intensive care, with $15-16$ beds for long-term residents. In each trial, the participants were a resident as a primary (local) user, one or more of her/his family members as secondary (remote) users, the personal nurse of the resident, and other care workers at the ward. The resident participants were selected and invited to participate by the care personnel who had the knowledge about the participants' health conditions and capability to participate. The trials lasted between 6-12 weeks.

The telepresence robot system installed in the primary users' rooms included the telepresence robot and its charging station, and a "call request button": by pressing a separate big button the resident could send an SMS request to the mobile phone of the family member to ask her/him to open 

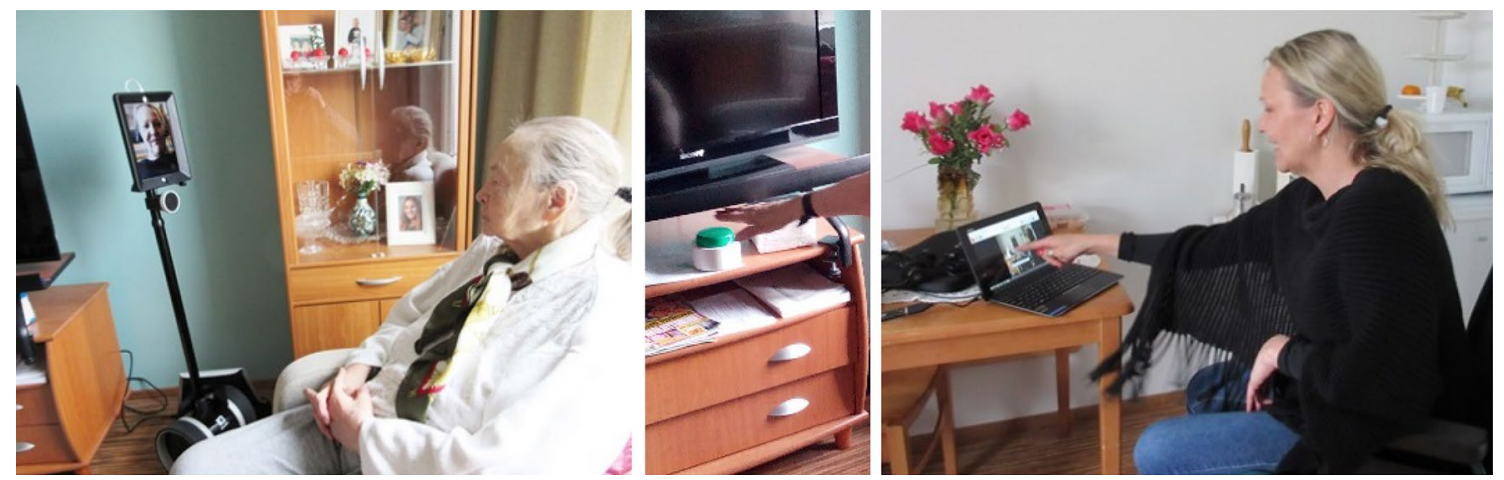

Fig. 1 The telepresence robot was placed in the room of the primary user in the care home (on the left). The resident could press a separate button to send an SMS request to her daughter to connect (in the middle). Her daughter used a laptop to connect with the resident (on the right)

the telepresence connection. The secondary users used laptops to open the video connection to the robot. The system is shown in Fig. 1.

The robot use in its driving mode was limited to the primary user's room to avoid unintended and unmonitored interactions with other residents at the ward. However, several driving sessions in the common spaces were separately arranged during the training and trials in order to get experience of them. In these sessions, researchers (also with the remote user) and care personnel collaborated to ensure that other residents were not recorded and no harm would be caused to them.

In each trial, the data was collected in pre- and post-interviews (of the resident, the family members, and the personal nurse), user observations, and keeping logs of the use of the robot and the call request buttons. In Trial 1, we also videotaped three call sessions (1-10 $\mathrm{min}$ ) of one daughter through the robot.

Care workers participated in focus group interviews after the trials: three care workers at the first facility (Trial 1) and five care workers and the manager at the second facility (Trials 2 and 3).

The results of the very first trial already indicated that care workers are worried about many ethical issues related to mobile telepresence at the ward [8]. In order to investigate this aspect more, we arranged an online questionnaire survey to the care workers at the second facility (Trials 2 and 3) about their perspective and ethical considerations of the telepresence robot in the care facility context. The questionnaire consisted of statements in five sections, of which we report three for the purpose of this article: (1) opening and closing the telepresence connection, (2) acceptable spaces for the remote visitor to go by using the robot and (3) acceptable activities for the remote visitor to participate in by using the robot. Each section contained 4-5 statements. The responses were given by using a 6-point Likert scale from "Totally disagree" to "Totally agree".
The data collection methods are summarized in Fig. 2. The study setting was accepted by the facility management and the Ethical Committee of the first author's affiliation (Trial 1), and by the facility management and the municipality responsible for providing the local elderly care services (Trials 2 and 3). All participants signed an informed consent form for taking part in the study.

\section{Results}

The use of the telepresence robot during the three trials is summarized in Table 3.

The trials faced some technical difficulties and practical challenges that have been acknowledged earlier as well (e.g. [22]), such as connectivity failures due to the poor or slow internet connection. Sometimes the connection broke many times and had to be re-established, which often explains the several successive shortish calls per one day. Audibility and setting the audio level was a challenge for primary users in Trials 1 and 3. For the latter resident, we set up an external loudspeaker in her room, to ensure her hearing.

\subsection{Residents' Perspective}

The residents did not have strong expectations for the robot: "Not really any expectations" (Trial 3 ) and "Of course I wish that it would be of some use at least" (Trial 2). Usefulness was related to communication and its clarity through the robot. The resident of the first trial looked forward to be in contact with her family members and, in particular, see her grandchildren through the robot.

After the trials, the experience of using the robot was positively geared for all three primary users. In particular, the video connection was appreciated, like in previous studies $[4,18,21,22]$, and seen to increase the feeling of family 


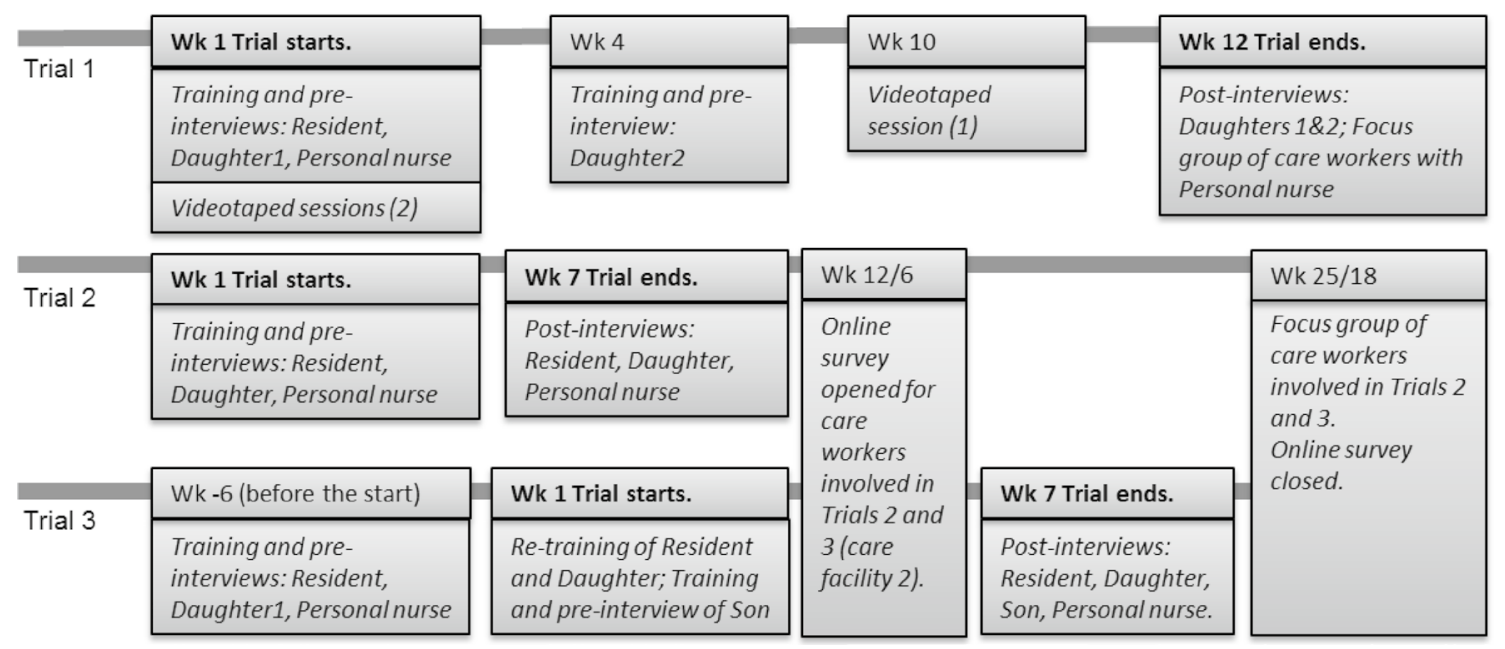

Fig. 2 The timeline of data collection during the trials. The trials were successive to each other. When there were overlapping events in Trial 2 and 3, the week count is shown for both (Trial2/Trial3). In
Trial 3, the first training and pre-interviews were carried six weeks before the actual trial (i.e. use of the robot) started

Table 3 Analysis of calls with the telepresence robot during the trials

\begin{tabular}{lllll}
\hline Trial & Length of trial & $\begin{array}{l}\text { Total N of } \\
\text { calls }\end{array}$ & Duration of calls & N of calls per week \\
\hline 1 & 12 weeks & 29 & $\begin{array}{l}\text { Typically } 5-10 \mathrm{~min} ; 21 \% \text { of calls at least } 10 \text { min } \\
\text { Variance } 2-34 \mathrm{~min}\end{array}$ & $2-5$ (excluding weeks 7-9) \\
2 & 18 & $\begin{array}{l}\text { Typically } 2-6 \mathrm{~min} ; 28 \% \text { of calls at least } 10 \mathrm{~min} \\
\text { Variance } 2-22 \text { min } \\
\text { Call duration varied a lot between } 2-16 \mathrm{~min} ; 36 \% \text { of } \\
\text { calls at least } 10 \text { min }\end{array}$ & $0-5$ (often several calls per day) \\
\hline
\end{tabular}

members' presence: "Yes it felt close." (Trial 3) and "Communication was kind of more natural [...] in particular with the children, it was terribly nice to see their expressions" (Trial 2). The telepresence connection allowed the primary user in Trial 1 to see her grandchild play piano. In Trial 2, the family opened a connection from their holiday trip.

The robot was felt easy to use in spite of the audibility problems. Two of three primary users found that the system is especially good to connect with family members but possibly not others: "I don't know if it suits any other but this kind of family use" (Trial 3).

The contents of the communication through the robot was mainly "everyday issues" and similar to when using a phone. Primary users preferred their mobile phones for quick checks and also for longer discussions because of better audibility. Privacy was not a concern and the primary users did not seem to mind that the connection could be opened any time by their family member: "We don't have any secrets from each other" (Trial 2). They were not interested in the robot following them to common spaces of the facility: "It is better that it is here in my own gaff' (Trial 2).

\subsection{Family Members' Perspective}

The telepresence connection created a feeling of presence of the resident for the family members and the presence was stronger than on the phone: "It was like a short visit [to the resident]" (Trial 3 ). One of the participants believed that her mother felt the same about their presence: "She seemed, somehow, so happy every time she realized that aha, there's somebody there now" (Trial 1). Seeing the physical condition and tiredness of the resident was important. One primary user (Trial 2) sometimes seemed to be little confused, and the family member explained this with the novelty of the system. In Trial 1, a family member told that sometimes their mother was less able to concentrate on the video image compared to the voice on the phone.

The family members did not find that the contents of communication would have changed due to the robot. This is in line with the primary users' view. The number of phone calls decreased during the trials; using the robot replaced phone calls to some extent.

The main concerns of family members were related to privacy. In all trials, they raised up the bothersome issue of 
sometimes feeling like spying and "going to the resident's turf" (Trial 2), especially when the resident was not aware of the connection being opened (e.g. when sleeping). Family members showed active strategies, e.g. scheduling their calls according to the daily rhythm of the resident, to avoid these situations. The embarrassment was balanced by feelings of relief, reassurance and safety, when they saw the resident was well even s/he did not response to the call.

The secondary users wished that the resident would have more control over the call. The communication was felt onesided and "It was always a surprise what is happening on the other side" (Trial 3). Using the robot in a "surveillance mode" could be acceptable if the resident was suffering from dementia or similar illness, the resident had fallen or been in an accident, or the robot was genuinely only in personal family use. Also in these conditions, the resident would need to agree with the possibility of surveillance. Furthermore, the participants commented that the primary user should be able to choose whom she wants to talk with and who is allowed to connect without a specific permission. The device should signal in a salient way that the connection is open.

The remote driving was not utilized much. It was experienced challenging due to the limited field of view to the surrounding space through the robot's camera. The main target of the secondary users was to see the resident in the room, and being able to turn the camera/display of the robot was enough. They did not find driving in the common spaces useful. Instead, that might even cause the feeling that the remote user is "more like lurking the nurses" (Trial 3).

\subsection{Care Workers' Perspective}

The care workers' experience of the trial was mainly positive: the robot increased the family members' presence to the residents, and the residents appeared to be brightened up after sessions of communication. Again, especially seeing the face and expressions of the relatives was crucial.

The robot's central function, perceived by the care workers, was that the robot enables family members to participate more in the daily life and activities of the facility. In particular, family members can more flexibly join the planning of care of the resident. In addition, they understand better the health condition of the resident as well as care work itself: "issues that we all day long deal with" (FG2). The robot was seen as an enabler to increase collaboration with families in facility care and improve family care, both which are general targets in the Finnish elderly care system nowadays.

There were some small occurrences in which the presence of a family member through the robot directly influenced the daily care work. For instance, a resident was in her room discussing with her daughter through the robot. A care worker popped at the door, when the daughter called her that the mother should take some rest. The care worker followed the daughter's suggestion. Overall, the care workers felt communication with residents to be different due to the presence of family members; they get "another touch" in their work. They explain issues better and "there's a certain difference in the customer service too" (FG2).

The limits of family members' participation in the care work were not clear. For instance, some care workers can accept family to participant in intimate activities such as washing a bed-ridden resident, if the resident has given permission. Other care workers would deny such participation. The care workers were also unsure, would they have the right to end the call for the resident, as opposing to the will of a (disturbing or controllable) family member. What if the resident was not able to say aloud her/his wish about ending the call? Moreover, if the calls were rejected or ended by a worker, would family members doubt that there is something suspicious going on?

In any case, the decision over accepting or rejecting the call should be local, by the resident. The care workers felt some anxiety because in the trials, the family member fully controlled opening the connection. An "Off-button" would be handy to (temporarily) let no calls come through, for instance, in sensitive care situations.

Remote driving of the robot in common areas was positively perceived to enable family members to participate even more to the daily life at the facility and to see the activity and condition of the resident. Remote driving however includes many challenges. First, the care workers found out that some residents (in common spaces in the facility) were confused about the robot and did not realize that the human voice was coming from the robot. At least one resident angrily told the robot to go away. Second, there is a risk that family members would evidence embarrassing situations with other residents (cf. [22]), and they could even record such situations in purpose. (This kind of situations or intentions were not observed during our trials.) As phrased by one care worker, the robot should only "shoot my relative to $m e "$ (FG1).

Third, family members could hear care workers' negotiations about other residents "Names would become public and possible ailments and troubles" (FG2). They did not like the idea "that you never know if there is a robot listening behind a corner" (FG2).

\subsection{Ethical Questionnaire for Care Workers}

We received 16 responses to our online survey questionnaire. The number is too small to allow statistical analysis, so the results are presented here in a descriptive manner and to complement the qualitative interview data. The 16 respondents included 13 care workers, two other members of the personnel, and a social worker; 15 of them worked at the ward and one in day care services provided at the 


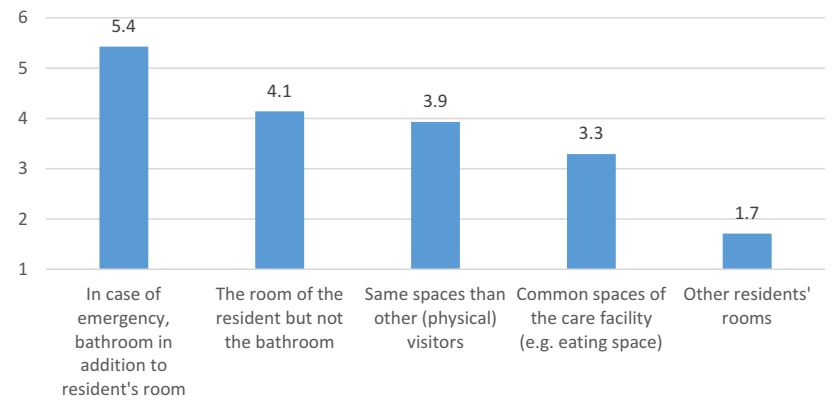

Fig. 3 Acceptance of different spaces that family members could visit through the robot $(1=$ low acceptance, $6=$ high acceptance $)$

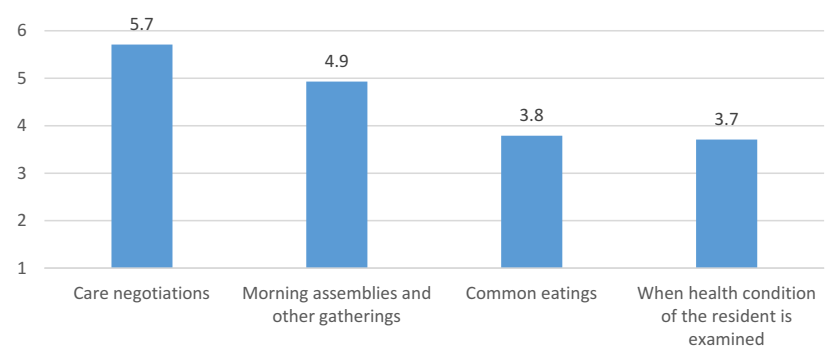

Fig. 4 Acceptance of different activities that family members could participate in through the robot $(1=$ low acceptance. $6=$ high acceptance)

care facility. Most (69\%) of them were 30-49 years old and all were female. Five respondents had used the robot themselves, five had monitored others using it and six had only seen it as turned off.

The care workers were most approving of the idea that in case of an emergency, family members could visit the resident's room and also bathroom (Fig. 3). For non-emergent visits, the approval was moderate for visiting the room of the resident as well as the same spaces than physical visitors (dining room excluded). Visiting other residents' rooms was not seen acceptable. Regarding activities in the facility, the respondents perceived most acceptable that family members would participate in care negotiations and social gatherings outside the resident's room (Fig. 4). Common meals and health checks of the resident seem to be less acceptable activities.

The respondents were moderately in favor of that the resident should have active control over accepting calls through the robot (Fig. 5). In contradiction, they agreed that accepting calls would be easy enough only if it does not require any action from the resident. The resident should nevertheless be able to shut the connection possibility down for preferred times, and also care personnel might be allowed to do that. Closing the connection should not however be the responsibility of the elderly person alone.

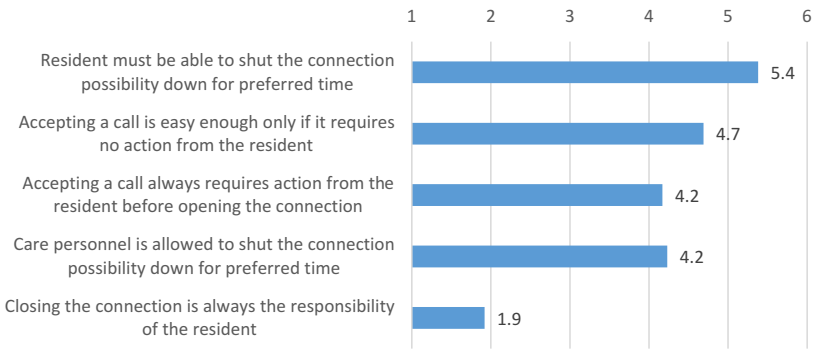

Fig. 5 Statements concerning the control over accepting and refusing calls through the robot ( $1=$ totally disagree, $6=$ totally agree $)$

\section{Discussion}

In the three field trials lasting from 6 to 12 weeks, we were able to confirm that telepresence robots do increase family members' presence to their elderly parents in residential care and thus positively affect the residents' wellbeing. Furthermore, telepresence robots have strong potential to increase family members' participation in the daily life in care facilities and in planning of care.

Apart from maturity of technology (connectivity and audibility issues; easy and safe remote driving), the main challenge seems to be the protection of privacy - of the resident as the primary user, of other residents in the facility, and of care workers. Most importantly, the family members and the care workers felt that the primary user should have control over accepting or rejecting the call, although this is recognized to be in conflict with the usability of the robot for elderly persons, as shown in the survey results. Before the trials, all participants accepted that the calling during the trials was fully controlled by the remote user. This setting led to situations or possibilities that were felt uneasy and unethical by the family members and care workers. It seems that the privacy and the usability of the system for the primary user need to be handled case by case, negotiated by the users themselves and also during the actual use. The privacy protection should however be the default.

Although in this study the residents and family members were not much interested in remote driving in common spaces (partially due to the practical difficulty of driving), the care workers suggested that it would increase the engagement of the family members. However, at the same time, the risk to invade other residents' privacy would increase also. It seems that to fully integrate telepresence robots into residential care and, in particular, use their mobility potential to increase the family engagement and residents' quality of life, clear guidelines are needed of how and where the robot can be used.

Based on the data collected in the study, we here present a draft for ethical guidelines for using mobile telepresence 
Table 4 Summarizing the results as a draft of ethical guidelines for using a mobile telepresence robot in residential care for communication between residents and family members

\begin{tabular}{lcc}
\hline Level of acceptance & Type of use for a mobile telepresence robot in residential care & Source in this study \\
\hline Well accepted use & $\begin{array}{l}\text { Using a telepresence robot to maintain and extend the existing } \\
\text { (positive) social, informal relationship between the resident and } \\
\text { family members (in a private space) }\end{array}$ & $\begin{array}{c}\text { Elderly residents, family members, care work- } \\
\text { ers (interviews) }\end{array}$ \\
& $\begin{array}{l}\text { Family members' participation in care negotiations with the resident } \\
\text { and the care worker (in a private space) }\end{array}$ & Care workers (interviews; ethical questionnaire) \\
& $\begin{array}{l}\text { Driving a telepresence robot everywhere in the resident's room, } \\
\text { including bathroom, in case of emergency }\end{array}$ & $\begin{array}{c}\text { Elderly residents (interviews) } \\
\text { Care workers (ethical questionnaire) }\end{array}$ \\
Moderately accepted use & $\begin{array}{c}\text { Family members' participation in informal social gatherings in com- } \\
\text { mon spaces }\end{array}$ & Care workers (ethical questionnaire; interviews) \\
& $\begin{array}{l}\text { Family members' participation in common meals or visiting in com- } \\
\text { mon dining space }\end{array}$ & Care workers (ethical questionnaire) \\
Visits to other residents' rooms & Care workers (ethical questionnaire; interviews) \\
Family members' participating in health checks or hygiene care of & Care workers (ethical questionnaire; interviews) \\
the resident &
\end{tabular}

robots for resident-family communication in residential care (Table 4).

In order to allow remote users to drive the robot in common spaces, required further activities should be asking a signed permission from all residents for letting the robot in to common spaces and asking a signed commitment from remote users that they do not misuse the information acquired through the robot.

There would still be challenges if some residents would refuse using the robot in common spaces. First of all, their choice should be respected, as the care facility is their home and they should be able to easily make individual choices regarding the services they use, their daily routines and their personal ways of living [11]. In order to allow using the robot in common spaces in spite of the refusal of some residents, technical solutions could be possible, for instance: "blind" autonomous driving of the robot between privacysecured areas, or AI-based pre-recognition of people who have signed the permission and automated blurring of others in the video image. In the latter, transfer of private audio would still be a problem to be solved.

As a boundary condition for using a telepresence robot to increase family presence and engagement, we still must raise the quality of the existing relationship between the resident and the elderly. In our trials, the family members were already actively communicating with their elderly parents, but lived far away and thus were interested in seeking additional ways to communicate. The robot would not create relationships from scratch, or improve problematic ones. However, the robot would still have potential in improving social connections of bed-ridden residents by letting them enjoy social events in the facility (e.g. remote-driven by a care worker), or arranging volunteer or even therapy workers to contact the residents through the robot.
Acknowledgements Open access funding provided by Technical Research Centre of Finland (VTT).

Funding This study was funded by Tekes (Grant Number $3724 / 31 / 2014)$ and Strategic Research Council at the Academy of Finland (Grant Number 292980).

\section{Compliance with Ethical Standards}

Conflict of interest The authors declare that they have no conflict of interest.

OpenAccess This article is distributed under the terms of the Creative Commons Attribution 4.0 International License (http://creativeco mmons.org/licenses/by/4.0/), which permits unrestricted use, distribution, and reproduction in any medium, provided you give appropriate credit to the original author(s) and the source, provide a link to the Creative Commons license, and indicate if changes were made.

\section{References}

1. Bekhet AK, Zauszniewski JA (2012) Mental health of elders in retirement communities: Is loneliness a key factor? Arch Psychiatr Nurs 26(3):214-224

2. Brownie S, Horstmanshof L (2011) The management of loneliness in aged care residents: an important therapeutic target for gerontological nursing. Geriatric Nurs 32(5):318-325

3. Pirhonen J (2017) Good human life in assisted living for older people: what the residents are able to do and be. Acta Universitatis Tamperensis 2272. Dissertation, University of Tampere

4. Cesta A, Cortellessa G, Orlandini A, Tiberio L (2016) Long-term evaluation of a telepresence robot for the elderly: methodology and ecological case study. Int J Social Robot 8(3):421-441

5. Nishio S, Ishiguro H, Hagita N (2007) Geminoid: teleoperated android of an existing person. In: de Pina Filho AC (ed) Humanoid robot. New Dev. I-Tech education and publishing, Vienna, pp 343-352 
6. Yamazaki R, Nishio S, Ishiguro H et al (2014) Acceptability of a teleoperated android by senior citizens in danish society: a case study on the application of an embodied communication medium to home care. Int J Social Robot 6(3):429-442

7. Coradeschi S, Loutfi A, Kristoffersson A, Rump S. Von, Cesta A, Cortellessa G, Gonzalez J (2011) Towards a methodology for longitudinal evaluation of social robotic telepresence for elderly. In: Proceedings on HRI 2011 workshop on social robotic telepresence, pp 1-7

8. Niemelä M, Aerschot L Van, Tammela A, Aaltonen I (2017) A telepresence robot in residential care: family increasingly present, personnel worried about privacy. In: Kheddar A (ed) Lecture Notes in computer science (including subseries Lecture Notes in Artificial Intelligence and Lecture Notes in Bioinformatics) Springer International Publishing AG, pp 85-94

9. Cutchin MP, Owen SV, Chang PFJ (2003) Becoming "at home" in assisted living residences: Exploring place integration processes. J Gerontol Ser B: Psychol Sci Soc Sci 58(4):S234-S243

10. Roth EG, Eckert JK (2011) The vernacular landscape of assisted living. J Ageing Stud 25(3):215-224

11. Zimmerman S, Scott AC, Park NS, Hall SA, Wetherby MM, Gruber-Baldini AL, Morgan LA (2003) Social engagement and its relationship to service provision in residential care and assisted living. Soc Work Res 27(1):6-18

12. Milligan C (2009) There's no place like home: Place and care in an ageing society. Ashgate, Farn-ham

13. Barredo RDV, Dudley TJ (2008) A descriptive study of losses associated with permanent long-term care placement. J Geriatr Phys Ther 31(3):87-92

14. Pirhonen J, Tiilikainen E, Pietilä I (2017) Ruptures of affiliation: social isolation in assisted living for older people. Age Soc 38:1-19

15. Pinquart M, Sorensen S (2001) Influences on loneliness in older adults: a meta-analysis. Basic Appl Soc Psychol 23(4):245-266

16. Park NS (2009) The relationship of social engagement to psychological well-being of older adults in assisted living facilities. J Appl Gerontol 28(4):461-481

17. Tomaka J, Thompson S, Palacios R (2006) The relation of social isolation, loneliness, and social support to disease outcomes among the elderly. J Age Health 18(3):359-384

18. Beer JM, Takayama L (2011) Mobile remote presence systems for older adults: acceptance, benefits, and concerns. In: Proceedings of the international conference on human robot interaction-HRI, vol 11, pp 19-26

19. Seelye AM, Wild KV, Larimer N, Maxwell S, Kearns P, Kaye JA (2012) Reactions to a remote-controlled video-communication robot in seniors' homes: a pilot study of feasibility and acceptance. Telemed J E-Health : The Off J Am Telemed Assoc 18(10):755-759
20. Gonzalez-Jimenez J, Galindo C, Gutierrez-Castaneda C (2013) Evaluation of a telepresence robot for the elderly: a spanish experience. In: Ferrández Vicente JM et al (eds) Natural and artificial models in computation and biology. Lecture notes in computer science 7930 Springer, Berlin, pp 141-150

21. Koceski S, Koceska N (2016) Evaluation of an assistive telepresence robot for elderly healthcare. J Med Syst 40:121

22. Moyle W, Jones C, Cooke M, O'Dwyer S, Sung B, Drummond S (2014) Connecting the person with dementia and family: a feasibility study of a telepresence robot. BMC Geriatr 14:7

23. Louie W-YG, Li J, Vaquero T, Nejat G (2015) Socially assistive robots for seniors living in residential care homes. In: Coleman D (ed) Human-robot interactions nova science publishers Inc, pp 76-107

Marketta Niemelä (M. Psych., Ph.D.) is a senior scientist at VTT Technical Research Centre of Finland Ltd. Her research focuses on humanrobot interaction and the potential of robotics in services, especially in health and elderly care. She is leading the research topic of healthcare and social robots at VTT and works as a project manager in both national and international projects.

Lina Van Aerschot (MSocSc., Ph.D.) works as a post-doctoral researcher in the Centre of Excellence in Ageing and Care at the University of Jyväskylä. Her research focuses on care of older people, different sources of help and use of services in the field of social and public policy.

Antti Tammela (LicSc (Tech), M.A. (Educ)) is a senior scientist at VTT Technical Research Centre of Finland Ltd. His has expertise on field trial implementation and study methods, human studies, creative environments and study methods, human-robot interaction, aged people, nursery environments, shopping environments, media studies and disabled people technical aids.

lina Aaltonen (D.Sci.(Tech.)) is a Research Scientist at VTT Technical Research Centre of Finland Ltd. Her research work is concentrated on human factors and user experience in several domains, including social and industrial robotics.

Hanna Lammi (M.A.) woks as a research scientist at VTT Technical Research Centre of Finland Ltd. Her expertise includes user experience and human-driven approach and she is especially interested in visual design. Currently, she is focusing on human-robot interaction and cocreation of service robots and transportation robots. 